\title{
Research incentive program for clinical surgical faculty associated with increases in research productivity
}

\author{
Anneke T. Schroen, MD, MPH, FACS, Monika J. Thielen, ART, BComm, Florence E. Turrentine, PhD, \\ Irving L. Kron, MD, and Craig L. Slingluff, Jr, MD
}

\begin{abstract}
Objective: To develop a research productivity scoring program within an academic department of surgery that would help realign incentives to encourage and reward research. Although research is highly valued in the academic mission, financial incentives are generally aligned to reward clinical productivity.
\end{abstract}

\begin{abstract}
Methods: A formula assigning points for publications and extramural grants was created and used to award a research incentive payment proportional to the research productivity score, beginning July 2007. Publication points reflect journal impact factor, author role, and manuscript type. Grant points reflect total funding and percentage of effort. Publication data were gathered from Web of Science/PubMed/Medline and grants data from the departmental grants office. An annual award is presented to the person with the greatest improvement. The research productivity score data after July 2007 were compared with control data for the 2 preceding years. A 33 -question survey to 28 clinical faculty was conducted after the first year to measure satisfaction and solicit constructive feedback.
\end{abstract}

Results: The mean annual point scores increased from the preresearch productivity score to the postresearch productivity score academic years (2180 vs 3389 , respectively, $P=.08$ ), with a significant change in the grant component score ( $272 \mathrm{vs} 801, P=.03$ ). Since research productivity score implementation, the operative case volumes increased $4.3 \%$ from 2006 to 2011 . With a response rate of $89 \%$, the survey indicated that $76 \%$ of the faculty wished to devote more time to research and $52 \%$ believed 1 or more research-related behaviors would change because of the research productivity score program.

Conclusions: An objective, transparent research incentive program, through both monetary incentives and recognition, can stimulate productivity and was well-received by faculty. (J Thorac Cardiovasc Surg 2012;144:1003-9)

Promoting and rewarding research productivity presents an important mechanism for upholding the tripartite mission of an academic institution. Although research is highly valued in the academic mission, financial incentives or other rewards are commonly aligned with clinical productivity. This can be accentuated in procedure-based fields such as surgery. Measuring and recognizing research productivity in an academic surgery department could reward research and thus keep the incentives aligned with the department's overall academic mission.

Various programs to reward and incentivize research have been described in academic medical departments, but less commonly in surgery. ${ }^{1}$ Whether this is because such programs are less often used in surgery or less often reported is unclear. ${ }^{1}$ Within surgery, a survey of academic orthopedic surgery departments showed $61 \%$ had some

\footnotetext{
From the Department of Surgery, University of Virginia, Charlottesville, Va. Disclosures: Authors have nothing to disclose with regard to commercial support. Received for publication Nov 21, 2011; revisions received June 1, 2012; accepted for publication July 25, 2012; available ahead of print Aug 27, 2012.

Address for reprints: Anneke T. Schroen, MD, MPH, FACS, Department of Surgery, University of Virginia, PO Box 800709, Charlottesville, VA 22908-0709 (E-mail: ats2x@virginia.edu).

$0022-5223 / \$ 36.00$

Copyright (C) 2012 by The American Association for Thoracic Surgery http://dx.doi.org/10.1016/j.jtcvs.2012.07.033
}

form of compensation system reflecting academic work Of these programs, $42 \%$ used a point system, with varying detail, to allocate this remuneration. ${ }^{2}$ Williams and colleagues ${ }^{3}$ described a comprehensive points system for a surgery department that covered research, education, and service activities. A qualitative assessment of this program demonstrated that participants valued recognition of their academic efforts as highly as receiving a financial reward. ${ }^{3}$ Finally, Weigel and colleagues ${ }^{4}$ provided a blueprint for developing an academic productivity incentive system within surgery that emphasizes objective metrics, faculty input, and maintenance of clinical productivity. This program's effect on academic productivity and faculty satisfaction have not yet been reported.

We sought to create a simple, transparent, flexible, and fair research productivity scoring program for our surgery department, composed of thoracic and cardiovascular surgery, general surgery, surgical oncology, pediatric surgery, transplant surgery, and acute care surgery divisions. The productivity scoring program focuses on elements that count for academic promotion, specifically peer-reviewed publications and external peer-reviewed funding. This program is also intended to provide data for monitoring research activity and discussing future directions of our research mission. We present both quantitative and 


\section{Abbreviations and Acronyms \\ $\mathrm{FYE}=$ fiscal years ending \\ $\mathrm{NIH}=$ National Institutes of Health \\ RPS $=$ research productivity score}

qualitative results from our 4-year experience with this research productivity scoring program.

\section{METHODS \\ RPS Formula}

A RPS was developed in 2007 as a composite formula assigning points for publications, grant funding, and oral research presentations. This novel formula was based on concepts represented in previous published scores. ${ }^{2-4}$ The formula was intended to give weighted scores reflective of the emphasis given academic products in the promotion and tenure process. Our formula sums scores for publications and external peer-reviewed funding during an academic or fiscal year extending from July 1 to the following June 30. In its initial iteration, the formula also included a score for select oral research presentations:

$$
\begin{aligned}
& \text { RPS }=\text { publications }+ \text { peer-reviewed funding }+ \text { oral research talks } \\
&= {[(\text { paper type } \times \text { author role } \times \text { impact factor } \times 10]} \\
&+[\text { funding as principal investigator } \\
&+(\text { funding as collaborator } \times 0.33)] \\
&+[(\text { type of talk } \times \text { impact factor } \times 5]
\end{aligned}
$$

These formula components are described in further detail in Table 1 and in the following paragraphs.

\section{Publications Component}

Publication points are determined by the journal impact factor, author role, and paper type. Data for this component were collected from PubMed, MEDLINE, Web of Science, and Journal Citation Reports by 2 of us (A.S., M.T.). Faculty are given 2 opportunities annually to check the accuracy and completeness of the publications found and to self-report additional publications. All self-reported publications are checked to verify the correct publications dates and avoid duplications. The print publication dates are used to determine inclusion within an academic year, and not electronic publication dates in advance of print. Impact factors are updated to reflect those from the most recent calendar year (eg, 2010 impact factors used for academic year 2010-2011). Journals with no impact factor are counted equivalent to the lowest impact factor of the journals represented that academic year. Book chapters and editorships are counted with an impact factor of 3.0 and 10.0, respectively. Book publication dates are verified to attribute the work to the appropriate year.

\section{Grant Funding Component}

Grant points are determined by the total funding received as a principal investigator, adjusted for the percentage of effort devoted to that grant, and salary support received as a collaborator. Total funding for grants as the principal investigator includes direct and indirect costs received within an academic year. Grant or salary support amounts are counted in thousands of dollars. Only extramural, peer-reviewed grants funding research are counted. Funding of clinical programs or services, direct philanthropic contributions, industry grants, and internal university grants are excluded. Data for this component are collected from the departmental financial office. Grants are attributed to the academic year according to the date the money was received by the institution.

\section{Oral Presentation Component}

Oral research presentation points are determined by the type of presentation and a measure of meeting prominence at which the presentation was given. Those at regional, national, or international meetings featuring results from personal research were counted. Presentation content was evaluated to distinguish those reporting on the faculty member's research from those serving mostly for continuing medical education. The proxy measure for meeting prominence was the impact factor of the journal associated with the meeting society, where available, or a value distinguishing regional from national or international meetings. Data for this component were collected from faculty curriculum vitae and meeting programs available through society websites. Oral presentation data required substantial effort to collect and had a negligible effect on the total scores. Therefore, presentations were not included in the calculations after academic year 2007-2008.

\section{RPS Implementation}

Before implementation in July 2007, the RPS program was debated at departmental faculty meetings and approved by clinical faculty members. All clinical faculty were included in the RPS program and were eligible for an incentive if a member of the faculty for at least 6 months of that academic year. After data collection for an academic year, individual research productivity reports are provided for review and feedback. Once all component points are finalized, the formula is used to award a research incentive payment proportional to the RPS. This payment is in addition to salary. Faculty members with a deficit in their individual cost center are eligible for $50 \%$ of the research incentive. Funds for the RPS program, derived from departmental administrative funds, total approximately $\$ 200,000$ annually. In addition to the calculated research productivity rewards, a bonus is awarded to the faculty member with greatest improvement from the previous year. That bonus amounts to $10 \%$ of the available funds for that year and is determined by the change in rank among faculty in the total productivity score and the absolute increase in the score compared with the previous year. Ideally, the award goes to the person who meets the designation of most improved according to both criteria. In other cases, the Faculty Advisory Committee of the Department of Surgery will review the data and make a recommendation to the Chair of Surgery. One choice is to divide the $10 \%$ funds between faculty members with the greatest improvement.

Finally, an annual report is produced each year with a presentation at a departmental faculty meeting. This facilitates public recognition of the department's research productivity and of exemplary efforts or improvements by individual faculty.

\section{Faculty Questionnaire}

In February 2009, a 33-question survey was conducted of the 28 clinical faculty members with active appointments. Survey questions queried the RPS program's perceived efficacy to stimulate faculty research efforts. Respondents were asked to rate the appropriateness of the relative point values assigned to academic products. The respondents were also asked to reflect on whether the RPS program had influenced certain research-related behaviors, such as selecting journals with greater impact factors, paying closer attention to author role or the percentage of effort on grants, or submitting more papers and grants. A 5-point Likert scare was used to quantify agreement with statements on the RPS program's perceived effectiveness and administration. This scale used 1 to indicate strong agreement and 5 to indicate strong disagreement with a statement. Respondents could also indicate "no opinion" for a particular statement. Finally, information on academic rank, tenure status, years on academic faculty, and ideal amount 
TABLE 1. Components measured for research productivity score calculation

\begin{tabular}{|c|c|c|c|}
\hline & \multicolumn{3}{|c|}{ Component: publications (P) } \\
\hline & Paper type (PT) & Author role (AR) & Impact factor (IF) \\
\hline \multirow[t]{7}{*}{ Scores assigned } & Peer-reviewed manuscript $=1.0$ & $\begin{array}{l}\text { First } / \text { last }=1.0 \\
\text { Second/next to last }=0.5\end{array}$ & $\begin{array}{l}\text { Journal's IF; if no IF listed, use lowest } \\
\text { IF in that academic year }\end{array}$ \\
\hline & Review article $=0.75$ & Other $=0.2$ & \\
\hline & Book chapter $=0.5$ & & \\
\hline & Case report $=0.25$ & & \\
\hline & Editorial $=0.25$ & & \\
\hline & Review of paper $=0.25$ & & Book chapter $=3.0$ \\
\hline & Letter $=0.1$ & & Book editorship $=10.5$ \\
\hline
\end{tabular}

Sample calculation: publication

Jones DR, Mack MJ, Patterson A, Cohn LH. A positive return on investment: research funding by the Thoracic Surgery Foundation for Research and

Education (TSFRE). J Thorac Cardiovasc Surg. 2011;141:1103-6.

$\mathrm{P}=[(\mathrm{PT} \times \mathrm{AR} \times \mathrm{IF}) \times 10]=[($ peer - reviewed manuscript $=1.0+$ first author for D Jones $=1.0 \times \mathrm{JTCVS}$ impact factor 2010 $=3.608) \times 10]$ $=36.08$ points

\begin{tabular}{|c|c|c|}
\hline & \multicolumn{2}{|c|}{ Component: funding (F) (limited to extramural, peer-reviewed grants) } \\
\hline & Funding as principal investigator (FPI) & Funding as collaborator (FC) \\
\hline Scores assigned & $\begin{array}{l}\text { Total grant money (in } \$ \text { thousands) received in } \\
\text { academic year } \times \% \text { effort on grant }\end{array}$ & Salary support as collaborator (in $\$$ thousands) \\
\hline
\end{tabular}

Sample calculation: funding

NIH-NHLBI R01 (PI: faculty): total notice of award \$371,025; received August 22, 2010; \% effort $=0.1$

NIH-NCI R01 (collaborator: faculty): salary support \$16,022; received July 1, 2010

$\mathrm{F}=[(\mathrm{FPI}+(\mathrm{FC} \times 0.33)]=[($ total grant $\$, \mathrm{k}=371.025 \times \%$ effort $=0.1)+($ salary support as collaborator, $\mathrm{k}=16.022 \times 0.33)]$ $=37.1+5.29=42.39$ points

Component: oral research talks (T) (limited to presentations of personal research results at regional, national, or international meetings)

\begin{tabular}{|c|c|c|}
\hline & Type of talk (TT) & Impact factor (IF) \\
\hline \multirow[t]{4}{*}{ Scores assigned } & Keynote $=1.0$ & IF for journal associated with society hosting meeting \\
\hline & $\begin{array}{l}\text { Invited research talk at national/international } \\
\text { meeting }=0.5\end{array}$ & \\
\hline & Abstract for oral presentation $=0.25$ & $\begin{array}{l}\text { For national/international meetings without associated } \\
\quad \text { journal }=3.0\end{array}$ \\
\hline & Invited research talk at regional meeting $=0.25$ & For regional meetings without associated journal $=1.0$ \\
\hline
\end{tabular}

Sample calculation: talks

Ailawadi G, Lau CL, Fedoruk LM, Smith PW, Kuhn C, Kozower BD, Kern JA, Peeler BB, Kron IL, Jones DR. Does reperfusion injury still cause significant mortality after lung transplantation? Presented at the American Association of Thoracic Surgery Meeting, San Diego, CA, May 2008.

$\mathrm{T}=[\mathrm{TT} \times \mathrm{IF}) \times 5]=[($ abstract for oral presentation $=0.25 \times \mathrm{JTCVS}$ IF $2007=3.354) \times 5]=4.19$ points

of time devoted to research compared with actual time devoted to research was obtained. All data were entered anonymously into a database before analysis. This survey was approved for exemption by the University of Virginia institutional review board (HSR 13998).

\section{Statistical Analysis}

Historical control data were collected for the fiscal years ending (FYE) 2006 and 2007 to calculate the RPS for these 2 years. Point totals and component subtotals were compared for FYE 2008 to 2011 after initiation of the RPS program with FYE 2006 to 2007 before RPS using Student $t$ test. The percentage of change in points for each year and the percentage of change in average faculty points is presented. The compared results are presented without the oral presentation component scores to achieve homogeneity across all years. The paired $t$-test was performed for 18 faculty members who were eligible for all 6 years of the study. The average publication, grant, and total points compared between FYE 2008 to 2011 and FYE 2006 to 2007 were assessed for these 18 faculty. Median values are reported for the Likert scale survey data. Finally, to offer context for academic productivity in the Department of Surgery reported during the years in which RPS was in effect, the following 2 measures are represented. Because academic productivity could theoretically affect clinical productivity, the clinic visit and operative case volumes for the department during FYE 2006 to 2011 are provided. Also, because grant funding levels can reflect economic and political factors, National Institutes of Health (NIH) grant funding trends to the University of Virginia School of Medicine as 
a whole from FYE 2006 to 2010 are provided for comparison. These data were obtained from the NIH CRISP on RePORT website. Academic productivity incentives were not uniformly used across the school of medicine. Analytic tests were performed with Stata, versions 7.0 and 11.0, software (StataCorp, College Station, Tex).

\section{RESULTS \\ RPS Results}

Between 27 and 33 clinical faculty were eligible for the RPS program in any given study year. All faculty were fulltime, and more than $90 \%$ held tenure-track positions. To evaluate the changes in research productivity over time, RPSs reflecting publications and extramural grants were tabulated for FYE 2006 through FYE 2011. These are shown in Figure 1 for the overall department (Figure 1, $A$ ) and for the mean points per faculty member (Figure 1, $B)$. For consistency, points for oral research presentations were not included in these scores, because those data were only collected for FYE 2006 through FYE 2008. The total point scores increased, for both publications and grants, when comparing the years before and after initiation of the RPS program (Table 2). These changes were statistically significant for grant funding and demonstrated

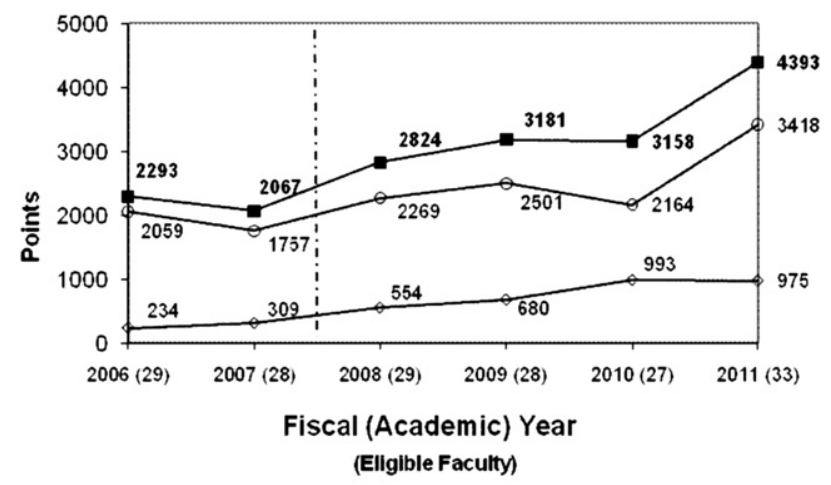

A

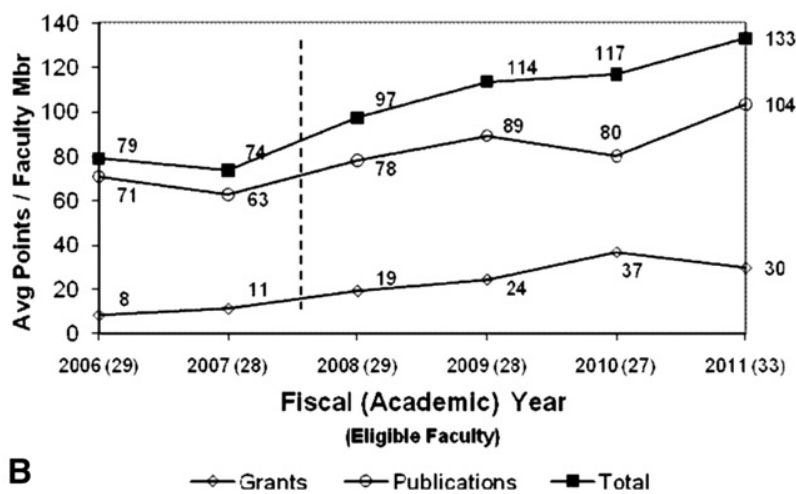

FIGURE 1. A, Research points generated from fiscal year ending ( $F Y E)$ 2006 to FYE 2011 (dashed line represents start of research productivity scoring program). B, Average research productivity points per faculty member from FYE 2006 to FYE 2011 (dashed line represents start of research productivity scoring program).
TABLE 2. Average points earned before and after implementation of research productivity score program

\begin{tabular}{lccc}
\hline & \multicolumn{2}{c}{ Mean points } & \\
\cline { 2 - 3 } \multicolumn{1}{c}{ Variable } & Before RPS & After RPS & $\boldsymbol{P}$ value \\
\hline Overall for department & $\mathrm{n}=2$ & $\mathrm{n}=4$ & \\
Publications & $1908 \pm 214$ & $2588 \pm 571$ & .20 \\
Grant funding & $272 \pm 53$ & $801 \pm 218$ & .03 \\
$\quad$ Total & $2180 \pm 160$ & $3389 \pm 689$ & .08 \\
Per eligible faculty member & $\mathrm{n}=28$ & $\mathrm{n}=29$ & \\
Publications & $67 \pm 6$ & $88 \pm 12$ & .09 \\
Grant funding & $10 \pm 2$ & $28 \pm 8$ & .04 \\
Total & $77 \pm 4$ & $115 \pm 15$ & .03 \\
Paired results for 18 faculty & $\mathrm{n}=18$ & $\mathrm{n}=18$ & \\
members eligible & & & \\
throughout study & & & \\
Publications & $78 \pm 60$ & $88 \pm 89$ & .37 \\
Grant funding & $15 \pm 39$ & $32 \pm 48$ & .04 \\
Total & $93 \pm 85$ & $120 \pm 126$ & .04 \\
\hline Data presented as mean \pm standard deviation. $R P S$, Research productivity score.
\end{tabular}

a trend toward significance for overall points. The mean points per eligible faculty member also increased over time, suggesting that the point increases were not solely because of an enlarging faculty. The changes based on mean points per eligible faculty were significant for grants and overall points, with a trend toward significance for publications.

The point difference before and after the institution of the RPS was also evaluated for the 18 faculty members who were eligible throughout the study. This demonstrated that the point increases in grants and total point scores were statistically significant within this subgroup of faculty, although the difference in publication point scores was not (Table 2).

Faculty members receiving the most improved designation typically increased their point totals during 2 consecutive years by 200 points or a percentage of improvement of approximately $70 \%$ to $230 \%$. In the program's first year, no clear candidate for most improved emerged; therefore, the award was not given. In the second year, a senior faculty member increased his publication productivity with 8 more peer-reviewed papers compared with the previous year. The third year produced a 3 -way tie among 2 junior faculty members and 1 senior faculty member. The dramatic point increases were earned by increased numbers of peerreviewed papers and new R01 or K08 grant awards. In the fourth year, a junior faculty member (assistant professor) increased the number of original peer-reviewed papers (excluding case reports) and review articles from 10 to 18 in 1 year.

Since RPS initiation, unique peer-reviewed publications averaged 97 annually, with 66 original papers, 13 review articles, and 19 case reports. The average journal impact factors increased from 3.185 in 2005 to 3.827 in 2010 . On average, 13 book chapters were produced annually. The 
total eligible grant revenues increased from 1.6 million in FYE 2006 to 4.3 million in FYE 2011.

During this period, for the 4 years ending in June 2011, the clinic visit volumes increased $4.7 \%$ and the operative case volumes increased $4.3 \%$ from FYE 2006 to FYE 2011 within our department. From FYE 2006 to FYE 2010, NIH funding to the School of Medicine declined $13 \%$ but funding to the Department of Surgery increased $59 \%$. The number of NIH awards declined $7 \%$ to the School of Medicine during this period, but doubled in the Department of Surgery.

The points for oral presentations the first year of the program totaled 246 , representing only $8.7 \%$ of the total points that year. A review of data from that year showed minimal changes in the overall rank of individual faculty or in the designation of the most improved faculty member, whether or not these presentation points were included. The disproportionate amount of work required to collect these data led to the discontinuation of giving points for oral presentations. This revision was also made to focus the rewards for academic productivity on the work that is recognized as most significant by the Promotions and Tenure Committee.

\section{Survey Results}

In $2009,25(89 \%)$ of 28 eligible faculty responded to a questionnaire about research activities and perceived effect of the RPS program. Respondents represented full professors $(44 \%)$, associate professors (16\%), assistant professors $(36 \%)$, and instructors $(4 \%)$. When asked to estimate the percentage of time devoted to research, $44 \%$ of respondents claimed $10 \%$ or less of their time for research, $36 \%$ of respondents claimed $11 \%$ to $39 \%$ of time, and $20 \%$ of respondents claimed $40 \%$ or more of time for research. No respondent wished to devote less time to research, and $76 \%$ of respondents reported they would like to spend more time on research. About $50 \%$ of the faculty indicated that their ideal versus actual amount of time spent on research was well matched. The other 50\% reported they would prefer to spend $10 \%$ to $40 \%$ more of their time on research.

Nearly all respondents $(91 \%)$ believed the RPS formula attributed an appropriate relative value to publications. Two thirds of respondents $(67 \%)$ thought that grant funding was appropriately valued within the formula, with $21 \%$ of faculty believing grants were overvalued. When asked whether the RPS program had influenced any particular researchrelated behaviors, $52 \%$ of respondents indicated that the RPS was likely to increase 1 or more research-related behaviors. Respondents $(40 \%)$ most commonly indicated that the system induced them to pay closer attention to author role in their papers. About $25 \%$ of respondents thought the RPS influenced their selection of journals for manuscript submission or spurred faster manuscript completion
TABLE 3. Self-reported influence of research productivity score program on research-related behavior $(n=25)$

The research productivity score program has induced me..

True $(\%)$

To finish publications faster

20

To look for journals with higher IFs for submission of my 28 manuscripts

To pay closer attention to author role in my manuscripts

To pay closer attention to my percentage of effort on grants with which I am involved

To submit more grant applications

IFs, Impact factors.

(Table 3). Finally, respondents reported their level of agreement with statements about the effect and fairness of the RPS using a Likert scale (Table 4). Faculty agreed strongly with rewarding research productivity and generally agreed that the RPS was sufficiently transparent and fair. Faculty also agreed that the RPS program could be beneficial in

TABLE 4. Strength of agreement with statements on research productivity score program influence and management $(n=25)$

\begin{tabular}{|c|c|c|}
\hline Statement & $\begin{array}{l}\text { Median score } \\
\text { (scale 1-5) }\end{array}$ & $\begin{array}{l}\text { No opinion } \\
(\%)\end{array}$ \\
\hline $\begin{array}{l}\text { In principle, rewarding research } \\
\text { productivity among clinical faculty is } \\
\text { appropriate }\end{array}$ & 1 & 0 \\
\hline $\begin{array}{l}\text { Rewarding research productivity among } \\
\text { clinical faculty with a financial } \\
\text { incentive is appropriate }\end{array}$ & 2 & 0 \\
\hline $\begin{array}{l}\text { My total points earned in the RPS in } \\
2007-2008 \text { were an accurate and fair } \\
\text { reflection of my research productivity }\end{array}$ & 2 & 12 \\
\hline $\begin{array}{l}\text { My total points earned in the RPS are } \\
\text { commensurate with the role of research } \\
\text { in my job description }\end{array}$ & 2 & 16 \\
\hline $\begin{array}{l}\text { A research incentive will influence my } \\
\text { research productivity in the future }\end{array}$ & 3 & 0 \\
\hline $\begin{array}{l}\text { A research incentive will influence the } \\
\text { department's research productivity in } \\
\text { the future }\end{array}$ & 3 & 0 \\
\hline $\begin{array}{l}\text { The RPS program will help in recruiting } \\
\text { faculty interested in research }\end{array}$ & 2 & 0 \\
\hline $\begin{array}{l}\text { The RPS program will help in retaining } \\
\text { faculty interested in research }\end{array}$ & 2 & 0 \\
\hline $\begin{array}{l}\text { Counting only publications and grants in } \\
\text { future RPS calculations is fair and } \\
\text { appropriate }\end{array}$ & 3.5 & 4 \\
\hline $\begin{array}{l}\text { Counting only external, peer-reviewed } \\
\text { grants in the RPS program is fair and } \\
\text { appropriate }\end{array}$ & 4 & 0 \\
\hline $\begin{array}{l}\text { The process used to calculate points for } \\
\text { the RPS program was sufficiently } \\
\text { transparent }\end{array}$ & 2 & 4 \\
\hline
\end{tabular}

Likert scale used from 1 to 5 to rate strength of agreement: 1 , strongly agree; 3 , neutral; 5, strongly disagree. RPS, Research productivity score. 
faculty recruitment and retention. After 1 year of this program, respondents were neutral about the program's influence on their own research productivity. Limiting points to grants and publications only, and specifically to extramural grants only, elicited the greatest amount of disagreement.

\section{DISCUSSION}

Research productivity, as measured by publications and extramural grants, has increased in our surgery department since implementation of a research productivity scoring system. This increase was observed for both the department overall and the average per faculty member and within the subgroup of faculty members present for the entire period before and after initiation of the RPS system. Furthermore, this increase did not come at the expense of clinical productivity. The increase in grant funding also could not be solely attributed to changes in NIH funding levels or grant availability through the American Recovery and Reinvestment Act of 2009. A theoretically more favorable grant funding environment should be reflected in increased grant funding throughout an institution. The program has been well received by faculty and viewed as fair, objective, and transparent. To what extent this program can be credited for incentivizing research productivity is unclear; however, the program has helped align rewards with an important part of our academic mission. This program features both monetary rewards and public recognition, both of which have been recognized as strong, if not equal, motivators. ${ }^{3,5,6}$ Rewards also constitute 1 of the 12 features of a "researchconducive environment," as promoted by Bland and Ruffin. ${ }^{6}$

Other putative strengths include incorporating both publications and grant funding. Some evidence has suggested that research productivity is primarily measured by grant funding levels in US academic institutions, but that publications and journal impact factors might play a more significant role within European institutions. ${ }^{7}$ The weighted measurement of publications and emphasis on grants with indirect cost recovery, as well as the objectivity, transparency, and flexibility of our system, meet the criteria for a productivity-based incentive program in surgery as outlined by Weigel and colleagues. ${ }^{4}$

Our program bears similarities to incentive systems described in other fields. Compensation strategies are, in some settings, being replaced by productivity-based remuneration. ${ }^{3}$ These programs rely increasingly on point systems as opposed to faculty seniority or departmental chair discretion. ${ }^{1,2}$ Other programs have reported determining rewards to include financial incentives, protected time, research space, or support personnel..$^{1-3,8-12}$ Similar to our findings, reported outcome measures generally show improvement in academic productivity without adversely affecting clinical revenues. ${ }^{8-11}$ In addition, faculty satisfaction with productivity-based programs is generally high, particularly if the programs are transparent and developed with faculty input. ${ }^{1,3,11,12}$

In assessing our program's success, its ability both to reward and incentivize research productivity needs to be evaluated. Rewards tend to promote and reinforce current behaviors; however, true incentives stimulate performance beyond expectations or in alignment with the organization's overall vision. ${ }^{2,5}$ Our RPS system has functioned well as a rewards program to date and arguably has incentivized productivity, as evidenced by point increases over time, marked increases in productivity by faculty who won the most-improved award, and increases seen within the same faculty members present throughout the study period. Proffering a reward that is substantial enough to influence individual behavior and group culture is integral to the success of a productivity incentive. Our research incentive payments have ranged, on average, from $\$ 750$ to $\$ 30,000$ among faculty who earned an incentive. Additionally, a long-term commitment to a research incentive program is necessary secondary to the significant time required in building and sustaining high levels of research productivity. The longitudinal data generated through this program provide effective monitoring of departmental productivity. Program assessment should include recognition that incentives, if great enough, could induce negative behaviors that seek to manipulate the reward. Monitoring behavior is therefore important in maintaining a culture of academic integrity while promoting productivity.

Future improvements could entail using the program more to direct research efforts and priorities. For instance, if novel or field-changing research is designated a priority, system modifications could include a quality metric. This is particularly important at a time of exponential volume increases in published biomedical studies. Even within surgery, 139 surgical journals publishing more than 22,000 articles annually were counted in $2004 .{ }^{13}$ Our formula currently reflects 1 estimate of quality by including a journal impact factor. However, to value the scientific contribution of an individual paper, a quality measure reflecting the number of citations could be added. The citation number would be counted for a 2- to 3-year period, and recognition of outstanding papers, as reflected in the citation number, would be awarded retroactively. Such a metric would distinguish papers that could be best categorized in the schema on paper importance by Allen and colleagues ${ }^{14}$ as making a "major addition to knowledge" in our field from those that would be categorized as "a useful step forward" or "for the record," thereby helping create more balance with the emphasis our formula inherently places on publication quantity. Although all bibliometric concepts have disadvantages, citation number could well be regarded as the most valid and readily accessible quality measure available. ${ }^{15}$ The program 
could also provide data to identify where resources would be best allocated to improve scholarly productivity throughout the department. Improvements in resource management could serve to incentivize faculty not producing the expected amount or quality of research, thereby elevating the productivity of the whole department and directing faculty development efforts. ${ }^{7}$ Finally, adjustments in the RPS formula could respond to critique on the appropriate valuation of RPS components. In our case, this could include adjusting the relative weight of publications and grants, broadening the criteria for included grants, and reinstituting a component for oral research presentations at major professional meetings.

Our finding that many faculty wished to spend more time on research was similar to that previously reported. ${ }^{4}$ The major barriers appear to be time and financial pressures, rather than a lack of research training. ${ }^{4,16}$ Difficulties in performing research to the level desired or expected are exacerbated in the current economic climate featuring constrained clinical reimbursements and grant funding levels. Productivity-based incentives, including recognition or remuneration, could therefore be useful to stimulate surgical research and maintain an equilibrium among all 3 academic missions.

We appreciate the assistance of Sandra Burks, RN, in coordinating the faculty survey.

\section{References}

1. Andreae MC, Blad K, Cabana MD. Physician compensation programs in academic medical centers. Health Care Manage Rev. 2006;31:251-8.
2. Emery SE, Gregory C. Physician incentives for academic productivity-an analysis of orthopaedic department compensation strategies. J Bone Joint Surg Am 2006;88A:2049-56.

3. Williams RG, Dunnington GL, Folse JR. The impact of a program for systematically recognizing and rewarding academic performance. Acad Med. 2003;78: 156-66.

4. Weigel RJ, Dracon G, Radhakrishnan R, Rho Y, Sevgen F, Dafoe DC. Incentive systems for academic productivity in a department of surgery. J Am Coll Surg. 2004;199:300-7.

5. Detsky AS, Baker MA. How to run a successful academic practice plan. JAMA 2007;298:799-801.

6. Bland CJ, Ruffin MT. Characteristics of a productive research environment-literature review. Acad Med. 1992;67:385-97.

7. Iyengar R, Wang Y, Chow J, Charney DS. An integrated approach to evaluate faculty members' research performance. Acad Med. 2009;84:1610-6.

8. Cramer JS, Ramalingam S, Rosenthal TC, Fox CH. Implementing a comprehensive relative value-based incentive plan in an academic family medicine department. Acad Med. 2000;75:1159-66.

9. Guss D. A simple plan-faculty compensation in an academic department of emergency medicine. Acad Emerg Med. 2002;9:654-7.

10. Tarquinio GT, Dittus RS, Byrne DW, Kaiser A, Neilson EG, Executive Committee of the Department of Medicine. Effects of performance-based compensation and faculty track on the clinical activity, research portfolio, and teaching mission of a large academic department of medicine. Acad Med. 2003;78: 690-701.

11. Brandt TL, Romme CR, LaRusso NF, Lindor KD. A novel incentive system for faculty in an academic medical center. Ann Intern Med. 2002;137: 738-43.

12. Hilton C, Fisher W, Lopez A, Sanders C. A relative value-based system for calculating faculty productivity in teaching, research, administration, and patient care. Acad Med. 1997;72:787-93.

13. Curtis WF, Hunter JG. What the impact factor means for surgery journals. World J Surg. 2006;30:1368-70.

14. Allen L, Jones C, Dolby K, Lynn D, Walport M. Looking for landmarks: the role of expert review and bibliometric analysis in evaluating scientific publication outputs. PlosOne. 2009;4:e5910.

15. Joiner KA. Evaluating faculty productivity in research: an interesting approach, but questions remain. Acad Med. 2009;84:1482-4.

16. Ko C, Whang E, Longmire W, McFadden D. Improving the surgeon's participation in research: is it a problem of training or priority? J Surg Res. 2000 91:5-8 